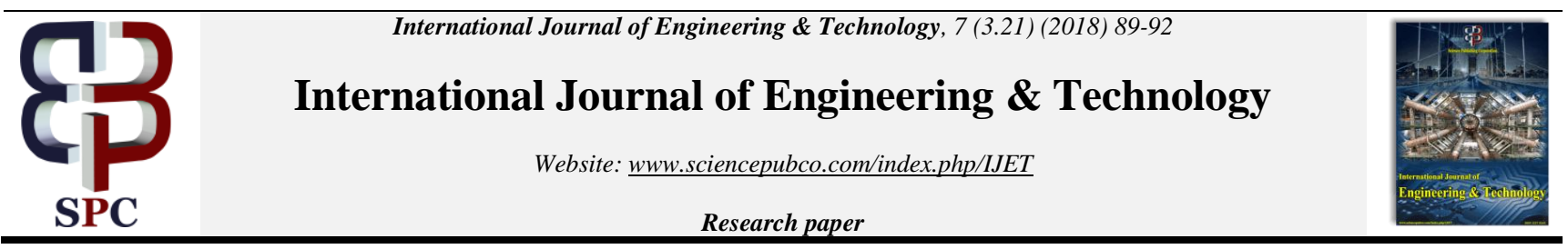

\title{
The Relationship between Stock Returns and Trading Hours: Evidence from Amman Stock Exchange
}

\author{
Buthiena Kharabsheh $^{1}$, Mahera Hani Megdadi ${ }^{2 *}$, Waheeb Abu-ulbeh ${ }^{3}$ \\ ${ }^{I}$ Department of Banking and Finance, Faculty of Economics and Administrative Science., Yarmouk University, Irbid-Jordan \\ ${ }^{2}$ Dammam University \\ ${ }^{3}$ Universiti Teknologi Malaysia \\ *Corresponding author E-mail: mmouqdadi@uod.edu.sa
}

\begin{abstract}
This study investigates the relationship between stock returns and trading hours for 22 shares listed on Amman Stock Exchange (ASE). We analyze the hourly trading data for the period Dec.2005 to Dec.2006. The two trading hours in ASE were split into four periods; first half of the first hour (10:00-10:30), second half of the first hour (10:30-11:00), first half of the second hour (11:00-11:30), and second half of the second hour (11:30-12:00). Using the Generalized Autoregressive Conditional Heteroscedasticity (GARCH) model, our results reveal that the hourly trading time significantly affects stock returns.
\end{abstract}

Keywords: Stock Returns; Seasonality; GARCH; Amman Stock Exchange; Trading Hours; Intraday; Hourly Data.

\section{Introduction}

The basic assumption of Efficient Market Hypothesis (EMH) is that asset prices reflect all publicly available information (1) thus implying that investors cannot rely on risk adjustment to achieve abnormal returns. Notwithstanding reiteration by Ritter (2) that fair prices and optimal allocation of investment resources are the principal characteristics of the capital market, several empirical papers provide evidence inconsistent with EMH.

Initially, Cross (3) then French (4) provided evidence that stock returns follow different patterns on different days of the week, followed by papers documenting positive or negative movements on a specific day, week or even month (5-7). These behavior patterns are known as seasonality and despite research by Keim and Stambaugh (8), Jaffe and Westerfield (7), Ariel (9), Al-Saad and Moosa (10) and Floros (11), documenting weekly and monthly changes including consistently higher stock returns in January, the day-of-the-week effect has received more attention in both theoretical and empirical analysis, with empirical papers $(3-6,12)$, reporting lower stock returns on Monday but higher on Friday. Various explanations have been offered suggesting measurement errors in security prices (13), while others favour timing of announcements since most firms releasing bad news at the end of the week $(4,14,15)$, although Al-Rjoub (16), amongst others, considers these explanations unsatisfactory.

The present paper is distinguished by two important points: empirical data are gathered hourly from Amman stock exchange, as the main objective of this study is to examine the relationship between stock returns and different trading hours during the trading day, thus focusing on the intraday effect. Secondly, abundant literature and empirical evidence is available from developed countries, while evidence on emerging markets is limited. The present study based on Amman Stock Exchange, one of the strongest in the region, could contribute significantly to the available literature.
The rest of the paper organized as follows. The next section provides the literature review and hypothesis development. Next, we present our sample and methodology followed by empirical results The last section concludes the study.

\section{Literature Review and Hypotheses Devel- opment}

Since first illustrated by Kelly (17) the day-of-the-week-effect remains a puzzle. Numerous studies document returns being negative on Monday and positive on Friday, from Cross (3) through subsequent decades to Angelidis and Lyroudi (18). Cross (3) provided early empirical evidence of this effect from the S\&P 500 Index over the period 1953 to 1970, while consistent evidence from Bombay Stock Exchange was provided by Poshakwale (19) over the period 1987-1994, and Berument, Inamlik (20) present supporting findings from Istanbul Stock Exchange over the period 1986 to 2003, recording stock return volatility as more on Mondays and less on Tuesdays.

From Jordan, Al-Rjoub (16), using a sample consisting of 2,682 daily observations through 1992 to 2002 documented similar unequal returns, albeit the lowest on Mondays and the highest on Thursdays. It is worth noting that before March 3rd 1999, the working week began on Monday and ended on Thursday. Similarly, Onoh and Ndu-Okereke (21) employing a sample from the Nigerian Stock Exchange over the period 2009 to 2015, show highest stock returns on Fridays. In their recent study of the dayof-the-week effect on Thai stocks from 2002 to 2015, Khanthavit and Chaowalerd (22) report negative returns on Mondays, but positive on Fridays, justified by order flow: buy-order flows on Friday create pressure on stock prices resulting in higher returns, while the sell-order flows create an opposite effect resulting in lower Monday stock returns.

However, other empirical studies document higher stock returns at the beginning of the week (Monday) and lower at the end $(23,24)$. 
For instance Aly, Mehdian (24) using a sample from the Egyptian stock market over the period 1998 to 2001, document higher stock returns at the beginning of the week (Monday) and lower at the end. A very recent study by $\mathrm{Lu}$ and Gao (25), examines the day-of-the-week effect in the Chinese stock market in light of the recent financial crisis, over the period 2003 to 2015 and documents the effect since 2004. Results are inconsistent with the literature, as Chinese stocks tend to have higher returns on Mondays and lower on Tuesdays, with the negative Tuesday effect appearing after controlling for the financial crisis. Since Japan and Australia have similar results, the authors conjecture the possibility of a spill-over effect from the U.S. stock market. while yet other studies report no significant differences between stock returns across the days of the week $(26,27)$.

In addition are the intraday anomalies: Half-of-the-Day Effects, where stock returns and trading volumes tend to be lower in the middle of a trading session; Last Hour and First Hour Effects, where stocks are lowest in the first hour of trading and highest in the last, and the Time-of-the-day anomaly where stock returns are higher in the first 45 and last 15 minutes of the trading day (28-30), while Çankaya, Eken (31) construct a sample using 15-minute intraday return values of the Istanbul Stock Exchange (ISE-100) index from the beginning of September 2007 to the end of 2009 to investigate how short selling and volatility differ during trading sessions. The conclusions illustrates that short selling activity differs significantly not only between different sessions of the day, but also trading hours. In a Polish study,Error! Hyperlink reference not valid. used EMH to test the day-of-the-week, and intraday effects for which they used 5-min returns for the period 2003 to 2008 , finding stock returns significantly and positively higher at the end of session.

Eyuboglu, Eyuboglu (32) examine the existence of both intra-day effect and day of the week effect using the aggregate index and 23 sub-indexes of Borsa Istanbul over the period 2005 to 2015. The findings confirmed the intra-day effect for all the sub-indexes tested in the study, for instance, 19 sectors have negative returns on Wednesdays, particularly, on afternoon sessions, while most sectors (around 16 sectors) have positive returns on Thursdays but in morning sessions. Regarding the day of the week effect, the empirical evidence documents this effect for only two sub-indexes Harris (33) provides empirical evidence from NYSE over the period 1981 to 1983 , reporting higher stock prices in the first 45 and last 5 minutes of trading, except Mondays, consistent with findings of Thaler (34), Dimson (35), and Levy (36), although Camino (29) found returns higher in the first hour of trading except Mondays and Wednesdays, and higher in the first and last 15 minutes. The tendency for prices to rise at opening and closing of trading is supported by Wood, McInish (37), Coroneo and Veredas (38) and Brooks, Hinich (28). A recent study by Berkman, Koch (39), using a large sample of 3000 US firms during the period 1996 to 2008 , testing the role of attention as a potential source of investor sentiment, results finding that stock returns tend to be higher at opening of trading for high market value firms and those whose stock value is difficult to estimate.

Illustrating patterns inconsistent with $\mathrm{EMH}$, a study by Branch and $\mathrm{Ma}$ (40) involving a large sample of US firms over a long period from 1994 to 2010, notes that when stock prices deviate from fair value principles this leads to mispricing, and give examples of significant negative relationships between overnight and intraday returns. Muravyev and $\mathrm{Ni}(41)$ investigate the day-night effect for US S\&P 500 index options: option returns tend to be negative overnight but have positive intraday returns, overnight negativity being at least partly due to volatility, tail risk, and other market conditions, whereas the positive effect during the trading day could be explained as option prices being exposed to higher volatility during the trading day, while Abhyankar, Ghosh (42) describe stock returns as trading in a U-shaped pattern, dipping in the mid-day. Tissaoui (43) reports that trading volume, return volatility and liquidity profiles all follow a U-shaped pattern within the trading day on the Tunisian Stock Exchange.
In this study, we investigate whether stock returns follow a certain pattern during the trading hours and therefore propose the following hypothesis:

H1: Mean returns in ASE are significantly different across the two trading hours.

Since we split the trading hours into four sessions, we propose the following sub hypotheses:

H1a: Mean returns in ASE are significantly different in first half of the first trading hour (10: 00-10: 30).

H1b: Mean returns in ASE are significantly different in the second half of the first trading hour (10:30-11:00).

H1c: Mean returns in ASE are significantly different in the first half of the second trading hour (11:00-11:30).

H1d: Mean returns in ASE are significantly different in the second half of the second trading hour (11:30-12:00).

\section{Sample and Methodology}

\subsection{Sample}

Our study sample comprises all the listed companies on Amman Stock Exchange (ASE) over the period Dec. 2005 to Dec. 2006, and includes all the listed companies in the first and the second markets in the banking, industrial, service and insurance sectors, but focuses however on the firms described as the most active in the market. Active trading can be defined in different ways such as trading days, trading size or volume of transactions (44). In the present study, trading days were used to determine the most active companies on ASE, which trades from 10:00 am to 12:00 midday five days a week (Sunday-Thursday). For the purpose of the study, each trading hour was split into two periods as illustrated below: D1: 10:00-10:30, D2: 10:30- 11:00, D3:11:00- 11:30 D4: 11:3012:00.

In order for a company to be included in the sample, it was required to meet the following criteria: First, the company should have been listed on ASE before 1/1/2005 and it should not be delisted or suspended during the study period i.e., Dec. 2005 to Dec. 2006. Second, at least $50 \%$ of the company's contracts should be executed in the trading day. Finally, during the study period, the company should not take any actions that affect stock trading, such as merger or stock split. Our final sample consists of 22 listed companies in three main sectors, namely the banking, service, and manufacturing sectors. We should note that the insurance sector was excluded from the study sample due to its comparatively inactive trading profile compared with the other sectors. The banking sector represents $43 \%$ of our final sample, the service sector $47 \%$, and the industrial sector only $10 \%$, since this sector is very active with huge amounts of data available for each company, thus limiting us to a manageable number of companies from the industrial sector. Data were collected from the ASE information centre, in addition to annual reports of the ASE.

Table 1 provides us with statistical figures of trading volume for the first and second markets in ASE. As seen in Table 1, trading volume decreased by $15.8 \%$ in 2006 compared with 2005 . The number of traded shares increased from 2,581.7 million in 2005 to $4,104.3$ million in 2006. Substantial increases are also noticed in the number of transactions executed from 2.4 million in 2005 to 3.4 million in 2006. Similarly, the number of transactions increased from 2,392.5 thousand in 2005 to $3,442.6$ thousand in 2006. Further, the ASE annual report indicated that on many days of the year in 2006 , the number of executed transactions was approximately 25,000 daily.

Table 1: This Table provides some trading indicators for both First \& Second Markets in ASE. All of these figures are taken from annual reports published by ASE.

\begin{tabular}{|l|l|l|}
\hline \multicolumn{1}{|c|}{ Performance measure } & Year 2005 & Year 2006 \\
\hline Trading Volume (JD Million) & 16871.1 & 14209.9 \\
\hline Number of Shares Traded (million) & 2581.7 & 4104.3 \\
\hline
\end{tabular}




\begin{tabular}{|l|l|l|}
\hline Number of Transactions (thousand) & 2392.5 & 3442.6 \\
\hline No. of Trade Days & 244 & 242 \\
\hline Turnover Ratio \% & 94.1 & 101.1 \\
\hline
\end{tabular}

Table 2 indicates the higher number of trades during the opening trading period, approximately 15,431 , whereas trading volume in the subsequent periods decreased to 12,339 , decreasing further in the third period to 11,090 , and rising again to 12,668 in the closing period, giving an average overall of 12,882 trades.

Table 2: Estimation of intraday Market Concentration

\begin{tabular}{|c|c|}
\hline Intraday Period & Number of Trades \\
\hline D1: $10: 00-10: 30$ & 15431 \\
\hline D2: $10: 30-11: 00$ & 12339 \\
\hline D3:11:00- $11: 30$ & 11090 \\
\hline D4: $11: 30-12: 00$. & 12668 \\
\hline
\end{tabular}

* Source: ASE annual report 2006.

\subsection{Methodology}

This study employs a generalised autoregressive conditional heteroskedasticity in mean (GARCH-M) model to test the relationship between trading hours and stocks return. This model was introduced by Bollerslev (45) and widely used to capture volatility of returns. Engle (46) describing the use of the ARCH/GARCH approach, states that they have become the widely popular and preferred tools of choice when dealing with time series heteroskedastic models, where the aim is to provide a volatility scale, somewhat akin to a standard deviation, for financial decision assessments in risk analysis regarding portfolio selection and derivative pricing.

The dependent variable in this study is the stock returns $\left(\mathrm{R}_{\mathrm{t}}\right)$ and this variable measured using the following equation:

$$
R_{t}=\ln P_{t^{-}} \ln P_{t-1}
$$

Where $\ln \mathrm{P}_{\mathrm{t}}$ is the natural logarithm of ASE price index at time $(\mathrm{t})$, $\ln \mathrm{P}_{\mathrm{t}-1}$ is the natural logarithm of ASE price index at time (t-1). Following French (4), Gibbons and Hess (6) we use a test to account for average return differences across the trading hours.

$$
\begin{aligned}
& \mathrm{R}_{\mathrm{it}}=\alpha_{\mathrm{wt}} \sum_{\mathrm{t}=1}^{2} d t+\partial_{\mathrm{it}} \sigma_{\mathrm{it}}^{2}+\varepsilon_{\mathrm{it}}, \varepsilon_{\mathrm{it}} \sim \mathrm{N}\left(\mathrm{O} \sigma^{2}{ }_{\mathrm{it}}\right) \\
& \sigma_{\text {it }}^{2}=\omega_{\mathrm{i}}+\varepsilon_{\text {it } \varepsilon \mathrm{t}-1}+\phi_{\mathrm{it}} \sigma^{2}{ }_{\mathrm{it}-1} \\
& \mathrm{i}=1 \ldots . .3 \\
& \mathrm{t}=1 \ldots . .2 \\
& \text { Where: }
\end{aligned}
$$

$\mathrm{R}_{\mathrm{it}}$ is the return calculated using equation (1)

$\sigma^{2}{ }_{i t}:$ is the conditional variance at period $t$.

$\mathrm{dt}$ : is a dummy variable for time interval so we have D1,D2,D3,D4 as we have four intervals for the two trading hours. D1 take the value (1) for the first interval in the first trading hour and zero otherwise. Similarly, D2 take the value (1) for the second interval in the first trading hour and zero otherwise. D3 and D4 follow the same pattern for the second trading hour.

\section{Results and Findings}

In this section, we present our results. Table 3 summarizes the results for the four periods during the 2-hour trading time. Again, we split the trading hours into four periods, dividing each trading hour into two periods as follows:

D1: 10:00-10:30, D2: 10:30- 11:00, D3:11:00- 11:30 D4: 11:3012:00.

In addition, we present our results according to industry, as our sample was constructed from the manufacturing, banking and service sectors. Table 3 provides the results for stock returns during the trading hours in Amman Stock exchange using GARCH model.
Table 3: Main Results This table presents the results using GARCH model. $\mathrm{P}$-values are reported in parenthesis. $*, * *$, and $* * *$ indicate statistical significance at the 10,5 and 1 percent levels, respectively.

\begin{tabular}{|l|l|l|l|}
\hline Interval & Manufacturing sector & Banking sector & $\begin{array}{l}\text { Service } \\
\text { sector }\end{array}$ \\
\hline D1 & $0.0023 * * *$ & $-0.0019 * * *$ & 0.00015 \\
& $(0.000)$ & $(0.004)$ & $(0.1149)$ \\
\hline D2 & $-0.0017 * * *$ & $0.0003 * * *$ & $0.0003 * * *$ \\
& $(0.000)$ & $(0.0000)$ & $(0.0051)$ \\
\hline D3 & $-0.0013 *$ & 0.0028 & 0.0003 \\
& $(0.0528)$ & $(0.5332)$ & $(0.8032)$ \\
\hline D4 & $-0.0019 * * *$ & 0.0002 & $0.0002 * * *$ \\
& $(0.0001)$ & $(0.9159)$ & $(0.000)$ \\
\hline
\end{tabular}

According to the figures in Table 3, our main hypothesis, which states that mean returns in ASE are significantly different across the two trading hours, is confirmed. As we can see in the three sectors, the returns vary across trading hours.

In the first interval i.e., D1, the stock returns are higher for manufacturing firms and lower for banks, while no effect was found for the service sector. These results lead us to accept our first subhypothesis, which states that mean returns in ASE are significantly different in the first half of the first trading hour (10: 00-10: 30). Our findings also reveal that in the second half of the first trading hour, stock returns are lower for manufacturing firms but higher for banking and service firms. These figures lead us to accept our second sub-hypothesis, which states that mean returns on ASE are significantly different in the second half of the first trading hour (10:30-11:00). The findings for the first trading hour are, to some extent, in line with Harris (33), Thaler (34), Dimson (35), Camino (29), Brooks, Hinich (28), Coroneo and Veredas (38) and Berkman, Koch (39), which all support the finding that stock returns tend to be higher at the beginning of the first trading hour.

Table 3 indicates that in the first half of the second trading hour, there is weak evidence that stock returns for manufacturing firms are lower, however, no differences in stock returns are found for either the banking or service firms. Regarding the closing time, the results shows that the second half of the second trading hour (11:30-12:00) is mixed for the three sectors. The effect is negative for manufacturing firms, insignificant for banking firms and positive for the service sector.

\section{Conclusion and Recommendations}

This study provides empirical evidence illustrating the relationship between hourly trading and stock returns on Amman stock exchange. The effect of hourly trading times on returns was clear in all three sectors during the two trading hours. However, the effects vary in terms of actuality, direction and industry as explained in the previous section. Based on their analysis, the researchers offer the following recommendations for investors in ASE. Regarding the banking sector, particularly, investors can buy stocks during the first half of the first hour, and sell them during the second half of the first trading hour. For the manufacturing firms, investors can sell their stocks during the first half of the first trading hour, whereas they can buy them during the second half of the first hour and during the second trading hour. Finally, investors are advised to sell service firms stocks during the second half of the first hour, and the second half of the second hour. It should be noted here, that the difficulty of coping with the vast amount of data generated constituted one of the main limitations of this study.

\section{References}

[1] Malkiel BG, Fama EF. Efficient capital markets: A review of theory and empirical work. The journal of Finance. 1970;25(2):383417.

[2] Ritter JR. The buying and selling behavior of individual investors at the turn of the year. The Journal of Finance. 1988;43(3):701-17. 
[3] Cross F. The behavior of stock prices on Fridays and Mondays. Financial analysts journal. 1973;29(6):67-9

[4] French KR. Stock returns and the weekend effect. Journal of Financial Economics. 1980;8(1):55-69.

[5] Berument H, Kiymaz H. The day of the week effect on stock market volatility. Journal of economics and finance. 2001;25(2):181-93.

[6] Gibbons MR, Hess P. Day of the Week Effects and Asset Returns. The Journal of Business. 1981;54(4):579-96.

[7] Jaffe J, Westerfield R. The week-end effect in common stock returns: the international evidence. The journal of finance. $1985 ; 40(2): 433-54$.

[8] Keim DB, Stambaugh RF. A further investigation of the weekend effect in stock returns. The journal of finance. 1984;39(3):819-35.

[9] Ariel RA. A monthly effect in stock returns. Journal of Financia Economics. 1987;18(1):161-74.

[10] Al-Saad K, Moosa IA. Seasonality in stock returns: evidence from an emerging market. Applied Financial Economics. 2005;15(1):6371.

[11] Floros C. The monthly and trading month effects in Greek stock market returns: 1996-2002. Managerial Finance. 2008;34(7):45364.

[12] Agrawal A, Tandon K. Anomalies or illusions? Evidence from stock markets in eighteen countries. Journal of International Money and Finance. 1994;13(1):83-106.

[13] Connolly RA. An examination of the robustness of the weekend effect. Journal of Financial and quantitative Analysis. 1989;24(2):133-69.

[14] Damodaran A. The weekend effect in information releases: A study of earnings and dividend announcements. The Review of Financial Studies. 1989;2(4):607-23.

[15] Patell JM, Wolfson MA. Good news, bad news, and the intraday timing of corporate disclosures. Accounting Review. 1982:509-27.

[16] Al-Rjoub SA. The daily return pattern in the Amman stock exchange and the weekend effect. Working papaer available at: https://papersssrncom/sol3/paperscfm?abstract_id=484782. 2004.

[17] Kelly FC. Why you win or lose: The psychology of speculation: Boston: Houghton Mifflin; 1930.

[18] Angelidis D, Lyroudi K, editors. Seasonalities in the French stock market: The day of the week anomaly. Multinational Finance Society meeting, July; 2004.

[19] Poshakwale S. Evidence on weak form efficiency and day of the week effect in the Indian stock market. Finance India. 1996;10(3):605-16.

[20] Berument H, Inamlik A, Kiymaz H. The day of the week effect on stock market volatility: Istanbul Stock Exchange. Iktisat, Isletme ve Finans. 2004;223:91-102.

[21] Onoh JO, Ndu-Okereke OE. Day of the Week Effect: Evidence from the Nigerian Stock Exchange. Working papaer available at: https://papersssrncom/sol3/paperscfm?abstract_id=2865131. 2016.

[22] Khanthavit A, Chaowalerd O. Revisiting the day-of-the-week effect in the Stock Exchange of Thailand. Journal of Business Administration. 2016;39:151.

[23] Al-Loughani N, Chappell D. Modelling the day-of-the-week effect in the Kuwait Stock Exchange: a nonlinear GARCH representation. Applied Financial Economics. 2001;11(4):353-9.

[24] Aly HY, Mehdian SM, Perry MJ. An analysis of day-of-the-week effects in the Egyptian stock market. International Journal of Business. 2004;9(3).

[25] Lu X, Gao H. The Day of the Week Effect in Chinese Stock Market. The Journal of Asian Finance, Economics and Business. 2016;3(3):17-26.

[26] Basher SA, Sadorsky P. Day-of-the-week effects in emerging stock markets. Applied Economics Letters. 2006;13(10):621-8.

[27] Santesmases M. An investigation of the Spanish stock market seasonalities. Journal of Business Finance \& Accounting. 1986;13(2):267-76.

[28] Brooks C, Hinich MJ, Patterson DM. Intraday patterns in the returns, bid-ask spreads, and trading volume on stocks traded on the new york stock exchange. Henley Business School, Reading University, 2003.

[29] Camino D. The role of information and trading volume on intradaily and weekly returns patterns in the Spanish stock market. Working papaer available at: https://wwwresearchgatenet/profile/David_Camino/publication/415 99927. 1996

[30] Harris L. A day-end transaction price anomaly. Journal of Financial and Quantitative Analysis. 1989;24(1):29-45.
[31] Cankaya S, Eken MH, Ulusoy V. The impact of short selling on intraday volatility: Evidence from the Istanbul stock exchange. 2012.

[32] Eyuboglu K, Eyuboglu S, Yamak R. Predicting Intra-Day and Day of the Week Anomalies in Turkish Stock Market. Romanian Economic Journal. 2016;18(59).

[33] Harris L. A transaction data study of weekly and intradaily patterns in stock returns. Journal of financial economics. 1986;16(1):99-117.

[34] Thaler R. Anomalies: seasonal movements in security prices II: weekend, holiday, turn of the month, and intraday effects. The Journal of Economic Perspectives. 1987;1(2):169-77.

[35] Dimson E. Stock market anomalies: New York: Cambridge University Press; 1988.

[36] Levy H. Fundamentals of investments: Pearson Education; 2002.

[37] Wood RA, McInish TH, Ord JK. An investigation of transactions data for NYSE stocks. The Journal of Finance. 1985;40(3):723-39.

[38] Coroneo L, Veredas D. Intradaily seasonality of returns distribution. A quantile regression approach and intradaily VaR estimation. Working paper available at: http://ssrn.com/abstract=945084, 2006.

[39] Berkman H, Koch PD, Tuttle L, Zhang YJ. Paying attention: overnight returns and the hidden cost of buying at the open. Journal of Financial and Quantitative Analysis. 2012;47(4):715-41.

[40] Branch BS, Ma A. Overnight return, the invisible hand behind intraday returns? working papaer available at: https://papersssrncom/sol3/paperscfm?abstract_id=2689719. 2015.

[41] Muravyev D, Ni X. Why Do Option Returns Change Sign from Day to Night? Working papaer available at: https://papersssrncom/sol3/paperscfm?abstract_id=2820264. 2016.

[42] Abhyankar A, Ghosh D, Levin E, Limmack R. Bid-ask Spreads, Trading Volume and Volatility: Intra-day Evidence from the London Stock Exchange. Journal of Business Finance \& Accounting. 1997;24(3):343-62.

[43] Tissaoui K. The intraday pattern of trading activity, return volatility and liquidity: Evidence from the emerging Tunisian stock exchange. International Journal of Economics and Finance. 2012;4(5):156.

[44] al-Abed MF, Al-Khouri RS. Evaluating Liquidity Using High Frequency Data: Yarmouk University; 2006.

[45] Bollerslev T. Generalized autoregressive conditional heteroskedasticity. Journal of econometrics. 1986;31(3):307-27.

[46] Engle R. GARCH 101: The use of ARCH/GARCH models in applied econometrics. The Journal of Economic Perspectives. 2001;15(4):157-68 